LICENÇA CC BY:

Artigo distribuído sob os termos

Creative Commons, permite uso e distribuição irrestrita em qualquer meio desde que o autor credite a fonte original.

\title{
ESTUDOS DO CORPO NA BASE NACIONAL COMUM CURRICULAR DO ENSINO MÉDIO
}

\author{
STUDIES ON THE BODY IN THE NATIONAL COMMON \\ CURRICULAR BASE FOR SECONDARY SCHOOL EDUCATION \\ ESTUDIOS DEL CORPO EN LA BASE NACIONAL COMÚN \\ CURRICULAR DE LA ENSEÑANZA SECUNDARIA \\ ÉTUDES DU CORPS À LA BASE NATIONALE COMMUNE DES \\ PROGRAMMES D'ÉTUDES DU LYCÉE.
}

Tiago de Brito Cruvinel ${ }^{1}$

'Instituto Federal de Minas Gerais, Betim, MG, Brasil.

Artigo recebido em: 20/03/2020

Aprovado em: 03/11/2020

Resumo: Este artigo tem por objetivo analisar como a Base Nacional Comum Curricular (BNCC) tem estruturado as práticas corporais na área de Linguagens e suas Tecnologias, especificamente no que diz respeito ao ensino de Arte (Artes Visuais, Dança, Música e Teatro) no Ensino Médio. Buscou-se verificar se as práticas corporais apresentadas no documento - estruturadas por meio de competências e habilidades específicas - abordam o corpo na perspectiva da inclusão, da diversidade, da diferença e da emancipação dos sujeitos. Além disso, é apresentado como a BNCC do Ensino Médio pode auxiliar o corpo docente da escola a impedir o retrocesso causado pela extrema direita no poder.

Palavras-chave: Educação; Teatro; Estudos do corpo; BNCC.

Abstract: This article analyzes how the National Common Curricular Base (BNCC) structures bodily expression in the area of Languages and its Technologies, specifically in relation to the teaching of Art (Visual Arts, Dance, Music and Theater) in Secondary Schools. It investigates whether the forms of bodily expression presented in the document - structured based on specific competencies and skills - look at the body from the perspective of inclusion, diversity, difference, and the emancipation of individuals. This work also promotes the idea that the BNCC for Secondary Schools can be a tool for teachers of the school, to prevent the backwards movement caused by the far right in power.

Keywords: Education; Theater; Bodily expression; BNCC.

Resumen: El artículo tiene como objetivo analizar cómo la Base Nacional Común Curricular (BNCC), en Brasil, ha estructurado las prácticas corporales en el área de Lenguajes y sus Tecnologías, específicamente con respecto a la enseñanza de Arte (Artes Visuales, Danza, Música y Teatro) en la escuela secundaria. Intentamos 
verificar si las prácticas corporales presentadas en el documento, estructuradas por medio de habilidades y capacidades específicas, abordan el cuerpo desde la perspectiva de la inclusión, de la diversidad, de la diferencia y de la emancipación de los sujetos. Además, se presenta cómo la BNCC puede ayudar a los profesores de la escuela a evitar el retroceso causado por la extrema derecha en el poder.

Palabras clave: Educación; Teatro; Estudios corporales; BNCC.

Résumé: Cet article vise à analyser la manière dont la Base Nationale Commune des Programmes d'Études au Brésil (BNCC) a structuré les pratiques corporelles dans le domaine des langages et leurs technologies (l'Art, l'Éducation Physique, la langue maternelle à l'étranger), en particulier en ce qui concerne l'enseignement des Arts en général (Les arts visuels, la danse, la musique et le théâtre) au lycée. Nous avons aussi étudié si les pratiques corporelles présentées dans le document - structurées par des compétences et des capacités spécifiques - abordent le corps en tentant compte de l'inclusion, la diversité, la différence et l'émancipation des sujets. En outre, nous faisons des propositions qui permettront à la BNCC d'aider l'école à empêcher la dégradation provoquée par l'extrême droite au pouvoir.

Mots clés: L'éducation; Le théâtre; Les Études corporelles; La BNCC.

\section{Introdução}

Todas as menções às questões de gênero e orientação sexual foram retiradas da Base Nacional Comum Curricular (BNCC) do Ensino Fundamental e do Ensino Médio por pressão da bancada evangélica do Congresso Nacional ${ }^{1}$. Na época da homologação da BNCC do Ensino Médio, em dezembro de 2018, alguns jornalistas chegaram a publicar que, embora os termos "gênero" e "orientação sexual" tivessem sido retirados, a questão da diversidade, como princípio constitucional, continuou presente no documento.

De fato, em um território utópico, estando a diversidade em sua plenitude presente na BNCC e fora dela, isto é, amplamente compreendida pela sociedade contemporânea brasileira, não teríamos problemas em relação à ausência dos termos citados, pois a multiplicidade, a igualdade, o diverso e as diferentes formas de ser e estar no mundo seriam princípios já assimilados pela sociedade. No entanto, não é isso que ocorre no Brasil. Em muitos casos, as pessoas ainda associam as questões de gênero, por exemplo, apenas à orientação sexual.

Dessa forma, esses termos são importantes, uma vez que eles (re)afirmam a luta política e auxiliam a esclarecer questões que são fundamentais de serem discutidas nas escolas durante os processos de ensino e de aprendizagem na vida e no mundo do trabalho.

Diferentes comunidades brasileiras têm sido preparadas historicamente, desde o processo de colonização, para compreender as questões de gênero apenas na perspectiva da religião cristã, quando o Estado é pensado de maneira progressista. Porém, a dinâmica da sociedade, na medida em que entende sua evolução, sofre alterações. O Brasil poderia estar presenciando uma grande revolução ao acompanhar, entender e respeitar a complexidade da vida humana. Assim, o que se reivindica, em nível global, de acordo com Judith Butler, é o 
reconhecimento, a valorização, o direito de aparecer, de poder exercitar a liberdade, ou seja, uma vida que possa ser vivida (BUTLER, 2018).

Para muitos políticos homens, heterossexuais, cisgêneros e brancos, esse tipo de reivindicação não é relevante, visto que eles não precisam lutar por um direito que a eles sempre foi concedido. Suas vidas sempre puderam ser vividas. Eles nunca foram vítimas de assassinato apenas por existirem. Logo, aquilo que não os afeta diretamente não se torna relevante e importante para ser discutido como política pública. Desse modo, quando o Estado passa a ser governado, em sua maioria, por esses homens, e é abandonado o princípio da laicidade, como ocorre no Brasil atual, é na escola que devem ser criados espaços de resistência. A educação torna-se transformadora e emancipatória quando ela consegue quebrar a lógica patriarcal e construir formas diversificadas de enxergar a vida em sociedade.

Portanto, ficamos com os seguintes questionamentos: teremos professores dispostos a discutirem as políticas de gênero com o risco real de serem atacados nas redes sociais e/ou na própria comunidade escolar? Como formar docentes sensíveis a essa problemática?

\section{A educação sexual e as políticas de gênero}

Recentemente, a Ministra dos Direitos Humanos, Damares Alves, afirmou que "o governo federal [em parceria com o Ministério da Educação] vai criar um canal para que pais de alunos possam reclamar de professores que, durante as aulas, atentem "contra a moral, a religião e a ética da família". Apesar de a ministra não ter explicado como será o funcionamento desse aplicativo e quando virá a cabo essa plataforma de controle social ditatorial, sabemos que o governo vigente foi eleito também por defender valores conservadores e dizer que iria combater o que se chamou de "ideologia de gênero" nas escolas. Além disso, a ministra supracitada, no início do ano de 2020, defendeu a "abstinência sexual para adolescentes" como método do que chamou de "preservação sexual"3.

Por "ideologia de gênero", o governo compreende que existem abusos por parte de docentes e de escritores de livros didáticos, que incentivam os estudantes a fazerem sexo na mais tenra idade, atentando contra a moral e os bons costumes cristãos. Além de incentivarem a homossexualidade, como eles colocam em seus discursos.

Sabemos que não há "ideologia de gênero" e muito menos que se incentiva alguém a ser LGBTI+, independentemente da idade. A expressão "ideologia de gênero" foi usada para mascarar o preconceito de gênero, sexo e raça do governo, ao estabelecer os princípios conservadores cristãos como verdades absolutas que deveriam ser vistas como eixo formador nos processos de ensino e aprendizagem.

O estudo de gênero nas escolas passa por outra perspectiva, cujo objetivo principal sempre foi proteger o corpo das crianças e dos adolescentes. Protege-se o corpo dando conhecimento aos estudantes. Esse tipo de conhecimento previne diferentes formas de abuso sexual, seja no seio familiar ou fora dele, quando se tem aula de orientação sexual, 
por exemplo. Evita-se também o suicídio quando a criança ou o jovem percebe-se LGBTI+ e diferente da estrutura social heteronormativa presente na comunidade em que vive. Aprendese igualmente que não deve haver nenhum tipo de diferença social, cultural e econômica entre homens e mulheres, entre outros tipos de proteção desses corpos.

A Just Like US, criada por Tim Ramsey, em Londres, na Inglaterra, é um exemplo interessante de uma ação que tem funcionado nas escolas em diferentes cidades da Inglaterra. Essa organização treina jovens LGBTI+ para visitarem escolas e serem referências aos estudantes. Eles visitam os espaços escolares e contam sobre como foram suas infâncias, o que tiveram que superar em termos de autoaceitação e de bullying, para apoiar qualquer outro estudante que seja LGBTI+ - ou que não saiba ainda que é - e empoderar alunos e alunas heterossexuais como aliados e aliadas. Assim, essas visitas, que são realizadas por meio de palestras e/ou workshops, mostram que o direito à igualdade é muito importante para a comunidade LGBTI+. De acordo com dados publicados pela Just Like Us, após as sessões nas escolas, $86 \%$ dos estudantes entendem por que todos deveriam se importar com as questões LGBTI+ ${ }^{4}$.

Ainda de acordo com Tim Ramsey, "há uma dissonância entre a orientação sexual dos pais e a orientação sexual dos filhos e, se não lidarmos com isso desde o nascimento, há o risco de criarmos ainda mais sofrimento e dor para os jovens". E continua: "o problema é que as narrativas heterossexuais [...] contam uma única versão de uma identidade. Você não precisa sofrer bullying para achar que você é inferior por ser quem é. Essa narrativa faz isso sozinha" $\left(\right.$ TED-OXFORD) ${ }^{5}$. De modo que "estamos falando de algo que vai muito além de ofensas leves e bullying; [...] jovens LGBT correm quatro vezes mais risco de tentarem o suicídio do que jovens heterossexuais; um a cada dois se autoflagela; seis em cada dez afirmam que isso afeta seu desempenho na escola" (TED-OXFORD).

Para Tim Ramsey, quando determinados pais questionam o trabalho que eles desenvolvem nas escolas, ele lança algumas perguntas retóricas que servem também para o contexto brasileiro: "Será que seu filho era novo demais para aprender a ser heterossexual?; "Ele era novo demais para ver a mamãe e o papai de mãos dadas no parquinho?"; "Novo demais para ver a história de Alladin com a princesa Jasmine? $?^{7 "}$ (TED-OXFORD).

Trabalhos como esses desenvolvidos pela Just Like Us deveriam ser parte da política educacional brasileira, uma vez que demonstram que a educação sexual e as políticas de gênero contribuem para diminuir a dissonância intergeracional que pode existir entre a família e o estudante em relação à educação sexual. Além disso, salvam vidas ao protegerem os corpos de nossos estudantes e lutarem contra a desigualdade social entre homens e mulheres.

Dessa forma, podemos nos perguntar: a BNCC do Ensino Médio será capaz de abarcar as questões de gênero e orientação sexual e de que modo o documento aborda as práticas corporais e sob quais perspectivas? 


\section{As práticas corporais e a BNCC}

Neste artigo, deter-me-ei apenas a responder, de modo mais objetivo, àquilo que está posto na BNCC (2018) e sobre sua relação com as práticas corporais nas Artes do Corpo. Existem outros pontos que devemos nos questionar ao analisar a política nacional e a maneira de se fazer arte e de se ensinar Arte em tempos de resistência. Tais reflexões já foram por mim publicadas $^{8}$ e não serão abordadas neste texto.

Ademais, as problemáticas que envolvem especificamente a criação da BNCC já foram também por mim analisadas (CRUVINEL, 2019a). Na ocasião, apresentei diferentes críticas sobre o processo de criação das versões que compuseram a BNCC do Ensino Médio. Neste artigo, não abordarei as explicações sobre esse processo, mas é importante ressaltar que há vários pontos que precisam ser de conhecimento anterior à análise sistemática da documentação.

\section{As diretrizes da BNCC}

A BNCC inicia-se apontando a necessidade da recriação das escolas em uma perspectiva que envolva condições de inclusão social, acesso à ciência, à tecnologia, à cultura e ao trabalho, em um cenário cada vez mais complexo e com diferentes dinâmicas sociais, cenário este pontuado pela BNCC e pelas Diretrizes Curriculares Nacionais do Ensino Médio de 2011 (DCNEM, 2011).

As demandas da sociedade contemporânea para a formação do Ensino Médio, às quais a documentação se refere, podem ser compreendidas por meio de distintos referenciais e princípios ideológicos para a criação das políticas públicas nas escolas.

Embora estejamos vivendo em um período conservador e sendo governados pela extrema direita, prefiro analisar o documento baseado naquilo que ele propõe. Isto é, dinâmicas sociais, fluidas e complexas exigem, de maneira conceitual e social, o entendimento da complexidade humana a partir também do estudo do corpo e dos seus diferentes modos de ser e estar no mundo, se olharmos em uma perspectiva fenomenológica (MERLEAU-PONTY, 2006). O que, consequentemente, irá afetar as práticas corporais a serem trabalhadas em sala de aula.

Desse modo, não se compreende como poderiam ser estudadas as dinâmicas sociais, de modo fluido e complexo, com base em princípios conservadores de gênero e suas relações de desigualdade entre homens e mulheres. Tudo que envolve política conservadora de direita caminha do lado oposto às ideias de dinâmicas sociais complexas, uma vez que o discurso conservador limita-se à análise do mundo apenas sob um único ponto de vista.

Ainda em relação à BNCC, a noção de juventude é definida por meio do parecer estabelecido pelo Conselho Nacional de Educação e pela Câmara de Educação Básica, n5, de 2011, os quais a descreveram como: 
[...] condição sócio-histórico-cultural de uma categoria de sujeitos que necessita ser considerada em suas múltiplas dimensões, com especificidades próprias que não estão restritas às dimensões biológica e etária, mas que se encontram articuladas com uma multiplicidade de atravessamentos sociais e culturais, produzindo múltiplas culturas juvenis ou muitas juventudes. (PARECER CNE/CEB n. 5/2011).

Ao levar em consideração as múltiplas dimensões sociais e culturais dos jovens, não os restringindo às dimensões biológicas e etárias e compreendendo-os a partir dos contextos em que estão inseridos, podemos ver que a BNCC abre caminho para que distintas práticas corporais sejam trabalhadas em sala de aula.

Não se trata mais de estudar apenas o corpo branco, o corpo do balé, o corpo magro, historicamente mais sistematizado no campo das Artes Cênicas. Trata-se de ampliar a noção de corpo. Afinal, de que corpo estávamos falando quando nos referíamos ao estudo do corpo?

\section{Na sala de aula}

É necessário, desde os primeiros dias de aula, quebrar os paradigmas estabelecidos pela mídia e pela sociedade conservadora. Recolocar, por exemplo, o corpo negro no centro das discussões. Recolocar o corpo trans no centro das discussões. Recolocar o corpo da periferia no centro das discussões. Recolocar o corpo afeminado no centro das discussões. Recolocar o corpo gordo no centro das discussões. Entre outros corpos. Ao recolocarmos tudo no centro das discussões, não se hierarquizam os sujeitos e entende-se que tudo deve ser debatido, discutido e experienciado com a mesma importância.

Ao trabalharmos práticas corporais que envolvam diferentes corpos, em diferentes contextos, levamos os estudantes a (re)pensarem, por exemplo, nas implicações sociais que envolvem o processo de transição de gênero. Levamos os nossos estudantes a se colocarem no lugar do outro e a criarem afeto e/ou se aceitarem, em termos de diversidade. Um sujeito afeminado, seja LGBTI+ ou não, quer chamar atenção, de modo intencional, ao ter traços ditos femininos em seu corpo? Não. Esses traços fazem parte de sua identidade.

De certo modo, é preciso entender que a BNCC do Ensino Médio não trabalha com a perspectiva de conteúdo, trabalha-se com a ideia de competências e habilidades específicas. Falarei mais disso adiante. Nesse sentido, o professor ou a professora ganha mais autonomia para trabalhar as problemáticas que ele ou ela julga fundamentais e que dialoguem com o documento, como a ideia de corpo político.

Como professor de Arte do Ensino Médio Integrado no Instituto Federal de Minas Gerais (IFMG), tenho me utilizado bastante da Performance Arte como um elo importante para os alunos e as alunas perceberem de que maneira um corpo pode se tornar um corpo político. Todas as performances que realizo no ambiente escolar passam pela perspectiva autobiográfica. Dessa maneira, os estudantes estão sempre questionando aspectos que, para eles, são muito importantes: padrões sociais, padrões de beleza, machismo versus feminismo, homofobia, entre outros pontos. 
No plano de ensino anual que venho realizando, especificamente em relação à linguagem teatral, os estudantes começam compreendendo a relação do corpo com o espaço não convencional, por meio da elaboração de uma coreografia que se desenvolve em diferentes espaços do ambiente escolar. No ano de 2019, trabalhamos com algumas coreografias de Pina Bausch. Depois, os alunos e as alunas criaram um Happening a partir dos pressupostos de Allan Kaprow, autor que foi amplamente estudado e debatido em sala de aula. Ao final, os estudantes desenvolveram uma performance artística com base nos estudos de Renato Cohen.

Como professor, tenho liberdade de escolher os conteúdos que serão trabalhados em sala de aula e quais serão os propulsores para as práticas corporais cênicas que serão desenvolvidas no ambiente escolar. Desse modo, sempre trabalho com práticas que respeitem, analisem e critiquem os diferentes corpos presentes na sociedade contemporânea. Além disso, sempre conseguimos discutir, por meio de diferentes obras cênicas e visuais, os distintos corpos presentes na sociedade e de que modo eles se tornam visíveis quando se tornam corpos políticos, isto é, quando deixam o anonimato e passam a viver como pessoas humanas com seus direitos preservados.

\section{Por uma escola que acolha as diversidades}

A BNCC enfatiza que: "considerar que há muitas juventudes implica organizar uma escola que acolha as diversidades, promovendo, de modo intencional e permanente, o respeito à pessoa humana e aos seus direitos" (BNCC, 2018, p.464, grifo dos autores). Portanto, toda e qualquer tentativa de cercear o professor ou a professora de trabalhar, de maneira intencional e permanente, as diversidades em sala de aula no que diz respeito à pessoa humana e seus direitos estaria contrariando a atual Lei de Diretrizes e Bases da Educação, a LDB, que incorporou a BNCC em sua lei.

Desse modo, é preciso esclarecer que, uma vez que a BNCC já está homologada e que, além disso, modificou a LDB, há formas de se aplicar o documento ao nosso favor. Ainda que o documento tenha sido construído de forma antidemocrática, projetos como "Escola sem Partido" podem perder força, se olharmos a BNCC na perspectiva progressista.

Compreendo que a BNCC do Ensino Médio pode nos ajudar a frear o retrocesso causado pela extrema direita no poder, pois, para a Base,

\footnotetext{
O mundo deve lhes ser apresentado como campo aberto para investigação e intervenção quanto a seus aspectos políticos, sociais, produtivos, ambientais e culturais, de modo que se sintam estimulados a equacionar e resolver questões legadas pelas gerações anteriores - e que se refletem nos contextos atuais -, abrindo-se criativamente para o novo. (2018, p.463, grifo meu).
}

A ideia de que há um conhecimento que seja neutro, sem nenhum pressuposto ideológico, corresponde a reduzir a atividade docente a um papel de mero reprodutor de conteúdo acrítico dentro de um sistema que poderíamos chamar de ditatorial. Portanto, quando se fala em campo aberto, na BNCC, almeja-se mostrar diferentes perspectivas aos 
estudantes, reconhecendo que todas têm pressupostos ideológicos, cabendo ao estudante do Ensino Médio, que não é uma tábula rasa, assimilar e analisar as problemáticas do mundo contemporâneo a partir de seus referenciais culturais e do conhecimento acadêmico construído.

\section{Análise da BNCC: competências e habilidades específicas}

As competências específicas da área de Linguagens e suas Tecnologias para o Ensino Médio, de acordo com a BNCC (2018), são:

1 - Compreender o funcionamento das diferentes linguagens e práticas culturais (artísticas, corporais e verbais) e mobilizar esses conhecimentos na recepção e produção de discursos nos diferentes campos de atuação social e nas diversas mídias, para ampliar as formas de participação social, o entendimento e as possibilidades de explicação e interpretação crítica da realidade e para continuar aprendendo.

2 - Compreender os processos identitários, conflitos e relações de poder que permeiam as práticas sociais de linguagem, respeitando as diversidades e a pluralidade de ideias e posições, e atuar socialmente com base em princípios e valores assentados na democracia, na igualdade e nos Direitos Humanos, exercitando o autoconhecimento, a empatia, o diálogo, a resolução de conflitos e a cooperação, e combatendo preconceitos de qualquer natureza.

3 - Utilizar diferentes linguagens (artísticas, corporais e verbais) para exercer, com autonomia e colaboração, protagonismo e autoria na vida pessoal e coletiva, de forma crítica, criativa, ética e solidária, defendendo pontos de vista que respeitem o outro e promovam os Direitos Humanos, a consciência socioambiental e o consumo responsável, em âmbito local, regional e global.

4 - Compreender os processos de produção e negociação de sentidos nas práticas corporais, reconhecendo-as e vivenciando-as como formas de expressão de valores e identidades, em uma perspectiva democrática e de respeito à diversidade.

5 - Compreender os processos de produção e negociação de sentidos nas práticas corporais, reconhecendo-as e vivenciando-as como formas de expressão de valores e identidades, em uma perspectiva democrática e de respeito à diversidade.

6 - Apreciar esteticamente as mais diversas produções artísticas e culturais, considerando suas características locais, regionais e globais, e mobilizar seus conhecimentos sobre as linguagens artísticas para dar significado e (re)construir produções autorais individuais e coletivas, exercendo protagonismo de maneira crítica e criativa, com respeito à diversidade de saberes, identidades e culturas. 
7- Mobilizar práticas de linguagem no universo digital, considerando as dimensões técnicas, críticas, criativas, éticas e estéticas, para expandir as formas de produzir sentidos, de engajar-se em práticas autorais e coletivas, e de aprender a aprender nos campos da ciência, cultura, trabalho, informação e vida pessoal e coletiva. (BNCC, 2018 p. 490).

Todas essas competências específicas podem ser estudadas e trabalhadas a partir de práticas corporais que irão ampliar a forma de participação social dos estudantes por meio da autonomia, da colaboração, do protagonismo na vida pessoal e coletiva. Há um destaque também importante para o desenvolvimento de ações que promovam os Direitos Humanos e a compreensão das diferentes formas de expressão de valores e identidades, de modo a se respeitar a diversidade de saberes, identidades e culturas. Assim, podemos ver que todas essas competências caminham no sentido de construir, com os estudantes, práticas corporais inclusivas, diversas e que visam à emancipação dos sujeitos e que combatam qualquer tipo de preconceito.

Em relação às habilidades específicas, cada competência terá cerca de quatro a seis habilidades. Entre as habilidades específicas que dialogam com o recorte deste artigo, podemos destacar:

(EM13LGG201) Utilizar as diversas linguagens (artísticas, corporais e verbais) em diferentes contextos, valorizando-as como fenômeno social, cultural, histórico, variável, heterogêneo e sensível aos contextos de uso.

(EM13LGG202) Analisar interesses, relações de poder e perspectivas de mundo nos discursos das diversas práticas de linguagem (artísticas, corporais e verbais), compreendendo criticamente o modo como circulam, constituem-se e (re)produzem significação e ideologias.

(EM13LGG203) Analisar os diálogos e os processos de disputa por legitimidade nas práticas de linguagem e em suas produções (artísticas, corporais e verbais).

(EM13LGG204) Dialogar e produzir entendimento mútuo, nas diversas linguagens (artísticas, corporais e verbais), com vistas ao interesse comum pautado em princípios e valores de equidade assentados na democracia e nos Direitos Humanos.

(EM13LGG301) Participar de processos de produção individual e colaborativa em diferentes linguagens (artísticas, corporais e verbais), levando em conta suas formas e seus funcionamentos, para produzir sentidos em diferentes contextos.

(EM13LGG302) Posicionar-se criticamente diante de diversas visões de mundo presentes nos discursos em diferentes linguagens, levando em conta seus contextos de produção e de circulação.

(EM13LGG305) Mapear e criar, por meio de práticas de linguagem, possibilidades de atuação social, política, artística e cultural para enfrentar desafios contemporâneos, discutindo princípios e objetivos dessa atuação de maneira crítica, criativa, solidária e ética.

(EM13LGG501) Selecionar e utilizar movimentos corporais de forma consciente e intencional para interagir socialmente em práticas corporais, de modo a estabelecer relações construtivas, empáticas, éticas e de respeito às diferenças. 
(EM13LGG502) Analisar criticamente preconceitos, estereótipos e relações de poder presentes nas práticas corporais, adotando posicionamento contrário a qualquer manifestação de injustiça e desrespeito a direitos humanos e valores democráticos.

(EM13LGG503) Vivenciar práticas corporais e significá-las em seu projeto de vida, como forma de autoconhecimento, autocuidado com o corpo e com a saúde, socialização e entretenimento.

(EM13LGG602) Fruir e apreciar esteticamente diversas manifestações artísticas e culturais, das locais às mundiais, assim como delas participar, de modo a aguçar continuamente a sensibilidade, a imaginação e a criatividade.

(EM13LGG603) Expressar-se e atuar em processos de criação autorais individuais e coletivos nas diferentes linguagens artísticas (artes visuais, audiovisual, dança, música e teatro) e nas intersecções entre elas, recorrendo a referências estéticas e culturais, conhecimentos de naturezas diversas (artísticos, históricos, sociais e políticos) e experiências individuais e coletivas.

(EM13LGG604) Relacionar as práticas artísticas às diferentes dimensões da vida social, cultural, política e econômica e identificar o processo de construção histórica dessas práticas. (BNCC, 2018, p.491-497).

É possível perceber que a BNCC não trata de conteúdos a serem trabalhados em sala de aula, mas de competências e habilidades específicas. Cabe aos estados brasileiros a criação de currículos próprios e a definição de seus conteúdos para cada eixo formativo, dentro da proposta da BNCC.

Desse modo, assim como as competências específicas, podemos ver que as habilidades, com destaque especial para as (EM13LGG501), (EM13LGG502) e (EM13LGG503), tornam o ensino de Arte progressista, visto que as habilidades mostram-se inclusivas, diversas, atualizadas e emancipadoras.

Muito se questiona em relação ao modo como se darão as avaliações dessas habilidades específicas, uma vez que elas surgem por meio de códigos. No entanto, é preciso atentar-se que, no caso do ensino de Arte, todas as habilidades específicas, com seus respectivos códigos, foram construídas de modo muito amplo, de tal forma que será impossível criar uma avaliação limitadora ou fatos que menosprezem o caráter subjetivo da Arte.

"(EM13LGG603) Expressar-se e atuar em processos de criação autorais individuais e coletivos nas diferentes linguagens artísticas", por exemplo, pode se dar de diferentes maneiras. Como avaliar este tipo de habilidade específica? A avaliação sempre se dará no campo subjetivo. Perceba que não se trata de avaliar a qualidade das produções, mas de valorizar as criações autorais individuais e coletivas nos processos criativos.

É claro que especialistas da área das Artes Cênicas poderiam acrescentar outras habilidades importantes para o ensino da Dança, da Música, do Teatro, da Performance e do Circo. Entretanto, não podemos negar que as habilidades específicas criadas já dariam conta 
da complexidade do ensino de Arte no Ensino Médio. Precisamos sempre relembrar que o objetivo do ensino de Arte na escola não é a formação de artistas, mas, principalmente, a formação de sujeitos críticos, criativos, éticos e solidários, conforme propõe a BNCC.

\section{Considerações Finais}

Inúmeras análises já foram escritas sobre a reforma do Ensino Médio e o processo de construção da BNCC. Chamo atenção aqui para o material que já está homologado e as formas de os professores e as professoras de arte (Artes Visuais, Teatro, Dança e/ou Música) usaremno ao seu favor.

Ao lermos o documento e selecionarmos as competências e as habilidades específicas, e entendendo que o ensino de Arte ainda segue obrigatório na LDB, não deveríamos fazer a leitura desse documento apenas pela via da negação política.

É importante lutarmos contra o obscurantismo, isto é, a falta de instrução e, em muitos casos, a ignorância em relação aos fundamentos do ensino da Arte e sua importância nas escolas. Como foi possível demonstrar neste artigo em relação às práticas corporais a serem trabalhadas em sala de aula com os estudantes do Ensino Médio, não há nenhum limitador de conteúdo e/ou de viés ideológico conservador. Muito pelo contrário, as competências e as habilidades específicas mostram-se atualizadas e fundamentais para o desenvolvimento crítico, criativo e social dos alunos e das alunas em um período em que a liberdade artística e a de ensinar seguem ameaçadas, como no período da ditadura vivido no passado.

\section{Referências}

BRASIL. Conselho Nacional de Educação (CNE). Parecer n. 5, de 4 de maio de 2011. Diretrizes Curriculares Nacionais para o Ensino Médio. Diário Oficial da União, Brasília, DF, 24 jan. 2012.

. Conselho Nacional de Educação (CNE). Parecer n. 5, de 4 de maio de 2011. Diretrizes Curriculares Nacionais para o Ensino Médio. Diário Oficial da União, Brasília, DF, 24 jan. 2012.

Base Nacional Comum Curricular: Ensino Médio. Brasília: MEC/Secretaria de Educação Básica, 2018.

BUTLER, Judith. Corpos em aliança e a política das ruas: notas para uma teoria performativa de assembleia. Rio de Janeiro: Civilização brasileira, 2018.

CRUVINEL, Tiago. A avaliação qualitativa do ensino de Arte no Ensino Médio. Urdimento (UDESC), v. 1, p. 77-95, 2019a.

CRUVINEL, Tiago. Gestão cultural e diversidade em tempos de resistência. In: Tiago Cruvinel e Vicente Concilio. (Org.). Pedagogia das Artes Cênicas: atuar e agir. 1. ed. Curitiba: Editora CRV, 2019b, v. 4, p. 19-30. 
MERLEAU-PONTY, Maurice. Psicologia e pedagogia da criança: curso da Sorbonne 19491952. São Paulo: Martins Fontes, 2006.

\section{Notas}

1 Balloussier, Anna Virginia. Bancada evangélica celebra retirada de questão de gênero de base curricular. Folha de S. Paulo. São Paulo. 07 de abril de 2017. Seção Educação. Disponível em: https://www1.folha.uol.com.br/educacao/2017/04/1873511-bancada-evangelica-celebra-retirada-de-questao-de-genero-de-base-curricular.shtml?origin=folha. Acesso em: 8 jan. 2020.

2 Sem autor. Damares cria canal para denunciar professores "contra a família". Exame. São Paulo. 20 de novembro de 2019. Disponível em: https://exame.abril.com.br/brasil/ damares-cria-canal-para-denunciar-professores-que-vao-contra-a-familia/. Acesso em: 20 de nov. 2019.

3 Sem autor. Damares cria canal para denunciar professores "contra a família". Exame. São Paulo. 20 de novembro de 2019. Disponível em: https://exame.abril.com.br/brasil/ damares-cria-canal-para-denunciar-professores-que-vao-contra-a-familia/. Acesso em: 20 de nov. 2019.

4 Disponível em: https://www.justlikeus.org/. Acesso em: 21 de nov. 2019.

$5 \quad$ Palestra "Is My Child Too Young to Learn About Being Gay?", realizada pelo TEDxOxford e publicada no Youtube no dia 8 de abril de 2019. Disponível em: https://www.youtube. com/watch?v=yCIBp3YOleM. Acesso em: 21 de nov. 2019.

$6 \quad$ Palestra "Is My Child Too Young to Learn About Being Gay?", realizada pelo TEDxOxford e publicada no Youtube no dia 8 de abril de 2019. Disponível em: https://www.youtube. com/watch?v=yCIBp3YOleM. Acesso em: 21 de nov. 2019.

$7 \quad$ Palestra "Is My Child Too Young to Learn About Being Gay?", realizada pelo TEDxOxford e publicada no Youtube no dia 8 de abril de 2019. Disponível em: https://www.youtube. com/watch?v=yCIBp3YOleM. Acesso em: 21 de nov. 2019.

8 Sobre a gestão cultural e a diversidade em tempos de resistência. Ver: CRUVINEL, Tiago. Gestão cultural e diversidade em tempos de resistência. In: Tiago Cruvinel e Vicente Concilio. (Org.). Pedagogia das Artes Cênicas: atuar e agir. 1. ed. Curitiba: Editora CRV, 2019b, v. 4 , p. $19-30$. 